\title{
DAMAGES OF THE KEEL BONE IN LAYING HENS - OVERVIEW OF THE ETIOLOGICAL ASPECTS
}

\author{
K. Uzunova ${ }^{1}$, L. Lazarov ${ }^{2 *}$ \\ ${ }^{1}$ Student, Faculty of Veterinary Medicine, Trakia University, Stara Zagora, Bulgaria \\ ${ }^{2}$ Department of Internal Noninfectious Diseases, Faculty of Veterinary Medicine, Trakia University, \\ Stara Zagora, Bulgaria
}

\begin{abstract}
The damages of the locomotor system and the skeletal system, in particular, are one of the major problems in the industrial poultry farming. The topic for the pathological changes in the keel bone in oviparous birds has become especially popular among scientists and researchers in recent years. The high incidence of keel bone damage (KBD) of laying hens in industrial complexes is one of the biggest welfare problems facing the industry. They lead to disturbance of the animal welfare, causing pain, limiting the ability to move and to perform the characteristic behaviour of the species. This in turn causes a decrease in productivity and unacceptably large losses not only for the individual producer but also for the whole sector. The problem with the KBD is widespread in Switzerland, Great Britain, the Nederland, Belgium, Germany, and Canada. Different genetic lines of laying hens are affected, as well as all types of breeding systems. In general, the etiological factors are reduced to three main groups genetic predisposition, unbalanced diet and imperfections in housing systems. The causes and influencing factors of KBD remain unknown to the research community - a circumstance that seriously complicates the development of effective strategies to reduce their occurrence and severity.
\end{abstract}

Key words: laying hens, keel bone, fractures, etiology

\section{OVERVIEW}

These days the animal welfare becomes an important part of animal husbandry. It must be and it is strictly observed. Sometimes considering this welfare, more damages could appear, especially in contemporary poultry. One of the major issues facing the egg production industry is keel bone damages (1, 2). After the 2012 EU directive (1999/74/EC) with which the European Union banns the conventional battery cages, this problem may worsen. Similar are trends in North America (16). Recently, more and more institutions and organizations are beginning to pay attention to animal welfare, especially in industrial animal husbandry. In addition to obtaining the highest possible production, the direction is also to ensure optimal living conditions so the current

\footnotetext{
*Correspondence to: Lazarin Lazarov, Department of Internal Noninfectious Diseases, Faculty of Veterinary Medicine, Trakia University, 6000 Stara Zagora, Bulgaria; Office tel.: +359 42 699 699; Cell: +359 988346 405; E-mail: lazarin.lazarov@trakia-uni.bg
}

animal species can perform their natural behaviour. In this way the production increases, which justifies the made in this direction investments. Poultry farming develops mainly in two directions - broiler chickens and laying hens are raised, as the requirements for the two sectors are different and breeders must take into account the physiological and biological characteristics of the particular species. Numerous studies have been conducted worldwide on hen's behaviour and the necessary conditions for realizing their natural instincts. The inability to provide these conditions to the birds causes damages of various kinds, which limit the health, welfare and productivity. The topic of this overview focuses on laying hens and in particular one of the major problems in this industrial sector the damages of the keel bone and its etiology.

The etiological factors, leading to $\mathrm{KBD}$, are reduced to three main groups - genetic predisposition, unbalanced diet, and some imperfections in housing systems. Regardless of the cause, the result is reduced productivity 
and/or increased mortality, leading to significant economic losses not only for the single producer but to the whole sector too. The damages are reduced to two main categories: fractures and deviations (3). Fractures are considered a defect in the architecture of the bones most often due to short-term traumatic effects with great force. Deviations are a result of prolonged exposures with low intensity. They are found mainly along the longitudinal axis of the bone, forming the so-called S-shape or appear as transverse depressions - C-shape (4-6).

\section{Genetic factors}

The anatomy and the location of the keel bone in birds is one of the reasons leading to increasing the risk of injury. From a selective point of view, laying hens have poorly developed pectoral muscles, which make the keel bone vulnerable to fractures. Despite the huge advances in genetics recently and the many years of observations and research, there is still no concrete data on the genetic predisposition of some laying breeds to a weaker skeletal system. Research in the field of genetics by differentiating two lines of laying hens - H-line и L-line, derived of Lohmann Selected Leghorn (LSL) hybrid was made (7). They are selected by their bone strength - the so-called ,bone index", which is given by the strength of the humerus and tibia and the radiographic density of the keel bone (8). H-line has higher bone index and the Lline - lower. This means that the genetically selected $\mathrm{H}$-line has a stronger bone structure therefore it is less prone to fractures and deformations of the keel bone in comparison with the L-line, which is more likely to have fractures and deformations. This leads to the conclusion that genetics is one of the main things that need to be considered in the selection of laying hens. The main idea in the process of selection of highly productive breeds of hens is to reduce the chances of technopathies. Because of geneticists' efforts in this direction, highly productive breeds are more resistant to fractures and deformities of the sternum than low-productive breeds (9). This is another evidence that in the aetiology of the pathologies of the keel bone, genetics takes a major position.

\section{Diet}

The strength of both bones and eggs does not depend only on the genetic talents of the individual. The medical and economic performance of animals is largely determined by the nutritional balance. The lack of some important nutrients can be a reason of the unappropriated development of bones, which may lead to damages. An important structural element of the skeletal system and of the eggshell as well is calcium. It is known that laying hens reach their sexual maturity at the age of 16 to 18 weeks (10). The ossification of the skeletal system though continues until approximately 40 weeks of age (11) and since hens start laying eggs once they get sexually matured, lots of the calcium is used for the forming for the eggshell instead for the ossification. That is the reason why several centimetres of the caudal part of the keel bone remains cartilaginous (12). One eggshell contains approximately $2 \mathrm{~g}$ calcium (13). The main source of calcium for laying hens is food. It delivers about 60 to $70 \%$ of the calcium needed for shell formation. The remaining 35$40 \%$ the birds obtain by resorption from their bones $(14,15)$. The intensive egg laying with age leads to a gradual "weakening" of the bones as not only the medullary but also the cortical part of the bone is involved as a source of calcium (16). The authors mention that laying hens between 16 and 31 weeks of age have used as much of the structural composition of their bones as is necessary for the production of 14 eggshells (17). This leads to the conclusion that in the absence of sufficient calcium in the diet of birds, higher levels will be extracted from the bones, which implies their fragility and is prerequisite for fractures and deformations. Other authors report that adding Omega-3 fatty acids to the diet of 50-days-old birds contributes to better bone growth and their higher density. Accordingly, the deficiency could lead to problems with mineralization and increase the risk of deformation. (18)

\section{Housing systems and management}

There are different types of housing systems for laying hens (commercial conventional cage, enriched colony cage and cage-free aviary housing systems) because of the differences in legislation and regulations and because of the preferences of specific manufacturers. The possibilities for providing the necessary area, ancillary facilities, etc. are decisive; the points of view on the "best conditions" are also different. At the end, all manufacturers strive to achieve the highest possible productivity with minimum effort and cost which may lead to some health problems 
in hens. The de- and repopulation of the halls is also the main reason for KBDs - about $62 \%$ of the keel bone fractures occur at depopulation (19). The main reason behind these damages is the caused stress. Large differences in systems also play a key role in laying hens' breeding $(20,21)$. In housing systems, special attention is paid to the perches (22). According to some authors more KBDs after laying (92\%) in hen, kept in conventional cages have been registered, in comparison with the birds, in which environment metal perches are absent (83\%) (23). Other researchers report that the rate of fractures of the keel bone is getting $10-34 \%$ higher after putting perches in organic farming systems (21).

The type of perches and the material used for it is also important for preventing KBD. Round metal perches cannot provide sufficient stability for birds, which confirms the results obtained. Rubber and therefore more flexible perches with a larger diameter take away from the force of the impact in case of accidental balance losing from the hen and it its more convenient for the birds to catch on them. This information could be useful in attempts to prevent keel bone injuries $(24,25)$. Perches coated with softer rubber could be used with the same success in cell housing systems (26). This not only alleviates the possible damage of the keel bone but also improves the grip of the bird while landing (27).

The percentage of laying hens, living in cages in which KBDs are registered is about 23-30\% (9), while in those bred freely, the percentage is $56-96 \%(20,28)$. According to the same authors, the reason is, because birds in cages have fewer abilities to move. These housing systems are preferred by most manufacturers because the costs for treatment/prevention are less. However, it is debatable whether this system has been developed and taken into account the needs and natural behaviour of laying hens and whether their well-being is ensured. Free-range housing systems, on the other hand, must be constructed in a way to allow hens to move freely to the different parts of it. It is reported report that the installation of ramps in commercial aviary systems reduces the falls by $55 \%$, collisions by $41 \%$, and the keel bone fractures by $24 \%$ (29).

Another problem, which is one of the etiological factors for KBD, is the insufficient lighting in the premises. It is intentionally reduced in order to prevent feather pecking and cannibalism between the birds (19). However, the hens need a certain amount of light to properly assess their movements and land safety (30). Natural sunlight, on the other hand, promotes the synthesis of Vitamin $\mathrm{D}$, in the absence of which the development of rachitis in young and adolescent birds is possible, as well as subsequent osteomalacia. Abrupt changes from light to dark and vice versa can also increase the risk of sternal fractures due to sudden stress and inability to adapt (22).

\section{CONCLUSION}

The most important etiological factor after proper genetic selection is the housing system and management, and in parts - the nutrition (31). From this, it can be concluded that properly selected birds with a good genetic profile and high bone index, placed in specially built housing systems with carefully calculated distances between the components, as well as the appropriate material for their manufacture would reduce the risk of KBD. A good and ontime investment will lead to a preserved animal welfare, higher production, and consequently better profits for both - the individual producer and the whole sector.

\section{REFERENCES}

1. FAWC. Opinion on Osteoporosis and Bone Fractures in Laying Hens. Farm Animal Welfare Council, London, UK. 2010.

2. FAWC. An open letter to Great Britain Governments: Keel bone fracture in laying hens, Farm Animal Welfare Council, London, UK. 2013.

3. Casey-Trott, T., L. L. T. Heerkens, M. Petrik, P. Regmi, L. Schrader, M. J. Toscano and T. Windowski. Review. Methods for assessment of keel bone damage in poultry. Poultry Science 94:2339-2350, 2015.

4. Fleming, R. H., H. A. McCormack, L. McTeir and C. C. Whitehead. Incidence, pathology and prevention of keel bone deformities in the laying hen. Br. Poult. Sci. 45:320-330, 2004.

5. Lay, D. C., R. M. Fulton, P. Y. Hester, D. M. Karcher, J. B. Kjaer, J. A. Mench, B. A. Mullens, R. C. Newberry, C. J. Nicol, N. P. O'Sullivan and R. E. Porter. Hen welfare in different housing systems. Poult. Sci. 90:278-294, 2011.

6. Habig, C., and O. Distl. Evaluation of bone strength, keel bone status, plumage condition and egg quality of two layer lines 
kept in small group housing systems. $B r$. Poult. Sci. 54:413-424, 2013.

7. Stratmann A., E. K. F. Fröhlich, S. G. Gebhardt-Henrich, A. HarlanderMatauschek, H. W"urbel, and M. J. Toscano. Genetic selection to increase bone strength affects prevalence of keel bone damage and egg parameters in commercially housed laying hens. Poult. Sci. 0:1-10. 2016. http://dx.doi.org/10.3382/ps/pew026

8. Bishop, S. C., R. H. Fleming, H. A. McCormack, D. K. Flock and C. C. Whitehead. Inheritance of bone characteristics affecting osteoporosis in laying hens. Br. Poult. Sci. 41:33-40. 2000.

9. Budgell, K.L., Silversides, F.G. Bone breakage in three strains of end-of-lay hens. Can. J. Anim. Sci. 84, 745-747. 2004.

10.Korver DR. Symposium: avian osteoporosis: measurement and ethical consideration - introduction. Poult Sci 83:183-183.10.1093/ps/83.2.183. 2004.

11.Buckner GD, Insko WM, Henry AH, Wachs EF, Maclaury DW. Rates of growth and calcification of the sternum of male and female new-Hampshire chickens. Poult Sci. 26:533-4. 1947.

12. Casey-Trott TM, Guerin MT, Sandilands V, Torrey S, Widowski TM. Rearing system affects prevalence of keel bone damage in laying hens: a longitudinal study of four consecutive flocks. Poultry Sci. 96(7):2029-39.10.3382/ps/pex026. 2017.

13.Kebreab, E., J. France, R. P. Kwakkel, S. Leeson, H. Darmani Kuni, and J. Dijkstra. Development and evaluation of a dynamic model of calcium and phosphorus flows in layers. Poult. Sci. 88:680-689. 2009.

14.Mueller, W. J., R. Schraer, and H. Schraer. Calcium metabolism and skeletal dynamics of laying pullets. J. Nutr. 84:20-26. 1964.

15.Buss, E. G., and R. B. Guyer. Bone parameters of thick and thin eggshell lines of chickens. Comp. Biochem. Physiol. 78A:449- 452. 1984.

16. Whitehead, C.C., Fleming, R.H. Osteoporosis in cage layers. Poult. Sci. 79, 1033-1041. 2000.

17.Cransberg, P.H., Parkinson, G.B., Wilson, S., Thorp, B.H. Sequential studies of skeletal calcium reserves and structural bone volume in a commercial layer flock. Br. Poult. Sci. 42, 260-265. 2001.

18.Toscano M. J., F. Booth, L. J. Wilkins, N. C. Avery, S. B. Brown, G. Richards and J. F. Tarlton. The effects of long (C20/22) and short (C18) chain omega-3 fatty acids on keel bone fractures, bone biomechanics, behavior, and egg production in free-range laying hens. Poult. Sci. 94:823-835. 2015. http://dx.doi.org/10.3382/ps/pev048

19.Gebhardt-Henrich, S. G. and E. K. F. Fröhlich. Early Onset of Laying and Bumblefoot Favor Keel Bone Fractures. Animals 2015, 5, 1192-1206; doi:10.3390/ani5040406. 2015.

20.Rodenburg, T. B., F. A. M. Tuyttens, K. de Reu, L. Herman, J. Zoons, and B. Sonck. Welfare assessment of laying hens in furnished cages and non-cage systems: an on-farm comparison. Anim. Welf. 17:363373. 2008.

21.Wilkins, L.J., Mckinstry, J.L., Avery, N.C., Knowles, T.G., Brown, S.N., Tarlton, J. and Nicol, C.J. Influence of housing system and design on bone strength and keel bone fractures in laying hens. Veteterinary Record 169: 414. 2011.

22.Harlander-Matauschek, A. \& Rodenburg, Bas \& Sandilands, Victoria \& Tobalske, B.W. \& Toscano, M.J. Causes of keel bone damage and their solutions in laying hens. World's Poultry Science Journal. 71. 461472. 10.1017/S0043933915002135. 2015.

23.Hester, P.Y., Enneking, S.A., Haley, B.K., Cheng, H.W., Einstein, M.E. And Rubin, D.A. The effect of perch availability during pullet rearing and egg laying on musculoskeletal health of caged White Leghorn hens. Poultry Science 92: 19721980. 2013.

24.Pickel, T., Scsholz, B. and Schrader, L. Perch material and diameter affects particular perching behaviours in laying hens. Applied Animal Behaviour Science 127: 37-42. 2010.

25.Pickel, T., Scsholz, B. and Schrader, L. Pressure load on keel bone and foot pads in perching laying hens in relation to perch design. Poultry Science 90: 715-24. 2011.

26.Stratmann, A., Toscano, M.J., Frohlich, E.K.F., Harlander-Matauschek, A. and Gebhardt-Henrich, S. Do soft perches reduce keel bone fractures in laying hens? PlosONe 10: e0122568. 2015b.

27.Scholz, B., Kjaer, J.B. and Srader, L. Analysis of landing behaviour of three layer lines on different perch designs. British Poultry Science 55: 419-426. 2014.

28.Käppeli, S., Gebhardt-Henrich, S.G., Frohlich, E., Pfulg, A. and Stoffel, M.H. Prevalence of keel bone deformities in 
Swiss laying hens. British Poultry Science 52: 531-536. 2011.

29.Stratmann, A., Frohlich, E.K.F., GebhardtHenrich, S., Harlander-Matauschek, A., Würbel, H. and Toscano, M.J. Modification of aviary design reduces incidence of falls, collisions and keel bone damage in laying hens. Applied Animal Behaviour Science 165: 112-123. 2015a.

30.Moinard, C., Statham, P., Haskell, M.J., Mccorquodale, C., Jones, R.B. and Green,
UZUNOVA K., et al.

P.R. Accuracy of laying hens in jumping upwards and downwards between perches in different light environments. Applied Animal Behaviour Science 85: 77-92. 2004b.

31.Fleming, R.H.; McCormack, H.A.; McTeir, L.; Whitehead, C.C. Relationships between genetic, environmental and nutritional factors influencing osteoporosis in laying hens. 2006, 47, 742-755. 